\title{
Transitoriedade da felicidade da criança brasileira*
}

The brief happiness in brazilian child

\author{
Aldaíza Sposati \\ Professora titular da PUC-SP, Programa de Pós-Graduação em Serviço Social, São Paulo/SP, Brasil.
}

nepsaspuc@gmail.com

Resumo: Este artigo tem por objetivo analisar o conteúdo, finalidade, legalidade, institucionalidade e impactos que o PCF - Programa Criança Feliz produzirá sobre os direitos de proteção integral da criança e do adolescente brasileiro. $\mathrm{O}$ decreto federal que o institucionaliza em território nacional é a peça-chave para verificar até onde ele respeita os sistemas federativos públicos de atenção social e observa os princípios democráticos, participativos e de controle social na gestão.

Palavras-chave: Criança feliz. Proteção integral da criança. Universalidade. Proteção básica. Direito da família.

\begin{abstract}
This article aims to analyze the content, purpose, legality, institutionality and impacts that the PCF-Happy Child Program will produce on the rights of integral protection of Brazilian children and adolescents. The federal decree that institutionalizes it in the national territory is the key to verify the extent to which it respects the federative public systems of social attention, and observes democratic principles, participatory, and social control in management.
\end{abstract}

Keywords: Happy child. Full protection of the child. Universality. Basic protection. Family law.

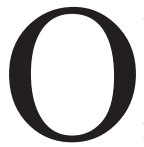
título deste artigo parte da seguinte observação: a União, por meio do decreto presidencial n. 8.869/16, cria o programa estatal Criança Feliz, nominação subjetiva que não esclarece o resultado desse investimento estatal em tempos de cortes orçamentários. O que esperar da ação estatal ou do gestor público na atenção à criança para que ela seja feliz?

A fragilidade, intencional ou não, da nomenclatura e do conteúdo do dispositivo legal sancionado não afiança, porém, as garantias legais instituídas para

* Este artigo resulta de estudos organizados pelo NCA/PUCSP, entre março a abril de 2017, feitos por: Eloisa Gabriel dos Santos, Eliana Garrafa, Fabiana Vicente de Moraes, Fabiana de Gouveia Pereira, Isabel Cristina Bueno da Silva, Kamila de Souza Gouveia, Marília Cerqueira Lima, Paola Cordeiro Pessanha, Paula Fernanda Avanzi, Valdenia Aparecida Paulino Lanfranchi, Tainah Rosa Resplande e Thabata Dapena Ribeiro. 
proteção integral à criança. A ausência de objetividade em explicitar a responsabilidade estatal na aplicação de recursos orçamentários públicos obstaculiza o exame da transparência da gestão pública na observância de padrões de probidade administrativa, necessários à gestão de uma atenção social em plenos e adequados padrões de cobertura. A omissão em revelar os resultados esperados, somada à não profissionalização dos agentes previstos para operá-los, causam profunda incerteza quanto à garantia de que direitos da criança, da família e da mulher sejam observados.

Afinal, o que a sociedade espera, objetivamente, do Estado brasileiro ao se responsabilizar pelo alcance subjetivo da felicidade de uma criança? Este artigo pretende trazer argumentos que permitam entender a que vem o PCF Programa Criança Feliz? ${ }^{1}$

\section{Antecedentes: inovação ou retrocesso.}

A gênese do PCF retornando ao século XIX é localizada no médico higienista Arthur Moncorvo $\mathrm{F}^{\circ},{ }^{2}$ que em 1880 fundou, no Rio de Janeiro, o Instituto de Proteção e Assistência à Infância, organização caritativa privada que realizava campanhas de assistência e educação e se preocupava em "ensinar as mães a serem mães melhores, segundo os padrões de higiene e cuidados" (Gomes, 2008, p. 40).

Uma das iniciativas tomadas na implementação do Instituto foi a Organização das Damas da Assistência à Infância, composto por mulheres das classes média

1. O PCF tem por objetivo promover o desenvolvimento humano a partir do apoio e do acompanhamento dos cuidados à criança prestados pela família que recebe transferência de renda. $\mathrm{O}$ trabalho consiste em visitas periódicas a moradias das crianças, realizadas por visitadores que orientarão as famílias a cuidar melhor de seus filhos.

2. "Moncorvo $\mathrm{F}^{\circ}$ desenvolveu cálculos sobre o impacto econômico da falta de atenção às crianças o custo econômico da mortalidade infantil preocupado em preservar a força de trabalho para a agricultura e para a indústria que começava a se instalar no país. De costas para as causas estruturais da condição de desigualdade social em que viviam, a preocupação das elites envolvidas nesses trabalhos era menos com o benefício às crianças pobres e mais com a preservação da ordem social" (Gomes, 2008, p. 42). 
e alta, ${ }^{3}$ com o propósito de promover novas estratégias de proteção à infância, tais como a confecção de roupas para os "menores carentes", organização de festas e arrecadação de donativos, preparação de material médico, distribuição de brinquedos em datas festivas. (Gomes, 2008, p. 41)

A LBA - Legião Brasileira de Assistência, órgão histórico sob gestão da primeira-dama, que mantinha clubes de mães onde as ensinava a cuidar dos recém-nascidos, foi subordinada ao Departamento Nacional da Criança do MS — Ministério da Saúde ${ }^{4}$ entre 1942 e 1967.

Essa preocupação em ensinar as mães, instalada sob vertente higienista entre os séculos XIX e XX, é reproduzida entre as justificativas do PCF no terceiro milênio. Permanece a ênfase disciplinar em que as mães, não mais em grupos de convivência, agora são abordadas individualmente, em sua moradia, por visitadores que ali desenvolvem ativíssima busca de expressões do amor materno. Para o médico e ministro do MDSA - Ministério do Desenvolvimento Social e do Desenvolvimento Agrário, em contraponto, a inspiração do PCF é contemporânea, respaldada no marco legal da primeira infância, em estudos da neurociência e em iniciativas estaduais e municipais.

A mais antiga dessas experiências é a Pastoral da Criança, organismo da Ação Social da CNBB - Conferência Nacional dos Bispos do Brasil fundada em correção 1983 pela pediatra Zilda Arns e por dom Geraldo Magela Agnelo para proporcionar o desenvolvimento integral da criança e a melhoria de sua qualidade de vida. Presente em mais de 3,7 mil municípios, tem sua operação vinculada ao MS, financiador de $50 \%$ de seus gastos.

Em entes federativos foram localizados os: PIM — Programa Primeira Infância Melhor, PMC — Programa Mãe Coruja, FQA — Programa Família que Acolhe e o PFP — Programa Família Paulista.

3. "A profilaxia residia na capacidade de oferecer o padrão de moralidade, felicidade, saúde e bem-estar das classes abastadas às crianças e famílias pobres das cidades" (Wadsworth,1999). O autor resgata a manifestação de hierarquia de classe e gênero que reforçavam o papel sagrado da mulher como esposa, mãe e provedora.

4. O ideário higienista implicou ações de disciplinamento da mulher para se manifestar como mãe extremosa. 
O PIM, ${ }^{5}$ instalado em 2003 no Rio Grande do Sul, pelo hoje ministro do MDSA, integra a política da primeira infância desse estado, sendo desenvolvido em parceria com os municípios e com ONGs. Regulado pela Lei estadual n. 12.544/06, é coordenado pela Secretaria de Saúde e busca orientar famílias, a partir de sua cultura, para que promovam, em consonância com a doutrina da proteção integral da criança, o desenvolvimento integral da criança desde a gestação até os cinco anos de idade, com ênfase na fase de zero a três anos.

O $\mathrm{PMC}^{6}$ pernambucano, instituído pela Lei n. 13.959/09, após dois decretos de 2007, tem por objetivo garantir qualidade na gestação e no pós-parto das mulheres usuárias do SUS, possibilitando o acesso ao parto humanizado, ao enxoval do recém-nascido, a proteção integral à mulher e à criança, fortalecer vínculos familiares, proporcionar educação para segurança alimentar e nutricional, prevenir a mortalidade infantil, ofertar documentação e cursos de formação, profissionalização e alfabetização.

$\mathrm{OFQA}^{7}$ foi implantado em Boa Vista (RO) pela Lei n. 1.545/13. Configura-se como política pública integral para primeira infância, alcançando da gestação aos seis anos. Tem por objetivos o acesso à saúde, educação, a promoção do desenvolvimento integral da criança, fortalecimento de laços de afeto entre as famílias e prover orientações sobre os direitos fundamentais previstos em lei. O FQA franqueia o acesso a serviços públicos, no que se distingue fortemente do

5. O PIM é parte integrante da política pública da primeira infância do estado do Rio Grande do Sul. Foi desenvolvido em parceria com os municípios e com ONGs em 2003 (Lei estadual n. 12.544/06) sob coordenação da Secretaria de Saúde com ênfase para a faixa etária de zero a três anos e em consonância com a doutrina da proteção integral. Visitadores presentes semanalmente nas casas das famílias as orientavam a executar atividades lúdicas para a promoção de habilidades das crianças. Cabia ao governo estadual realizar repasse financeiro mensal aos fundos sociais dos municípios e às ONGs que assinassem o termo de adesão ao programa.

6. O PMC atua no campo da saúde e intersetorialmente com a educação, desenvolvimento social e assistência social.

7. Crianças até seis anos, as que demandam atenção especial, que vivem em famílias inseridas no PBF são o público prioritário do FQA. São 7.720 beneficiários, sendo 840 gestantes. Trabalha o fortalecimento de competências nas famílias, apoio educacional e da assistência social, cuidados de saúde com as gestantes e as crianças. Conta com escola de pais denominada Universidade do Bebê, onde gestantes, mães e familiares têm acesso a informações sobre o desenvolvimento das crianças, oficinas de musicalização, coral e leitura. A presença de mães nessas atividades é condição para que seus filhos de dois a quatro anos tenham vaga em creche/casas mães. 
PCF, mostrando similitude com o programa chileno de transferência de renda, o Puentes. Disponibiliza o acesso a creches, escolas e unidades de saúde; ruas pavimentadas, abastecimento de luz, água, serviços de esgoto e coleta de lixo; oportunidade de emprego, moradia, transporte coletivo; atividades culturais e espaços para lazer.

O PFP $^{8}$ do estado de São Paulo é operado pela Secretaria de Desenvolvimento Social e tal como o PCF, produz ações intensivas com famílias que vivem em territórios de alta vulnerabilidade. Em similitude com o Puentes chileno, atua com a família por dois anos, distribuídos em: quatro meses de planejamento, doze meses de trabalho intensivo com as famílias, oito meses de acompanhamento pós-intervenção e avaliação de resultados.

Desse conjunto de experiências fica ressaltado o fato de que o ministro do MDSA, após quinze anos, transfere sua experiência sulina do campo da saúde para o campo da assistência social. Com isso, atropela o SUS e o Suas para criar a logomarca Criança Feliz, embalada pelos braços da mulher de vida precária, que nada tem de cuidados para seus braços, além de gastá-los na sobrevida cotidiana.

A ausência de articulações potentes que envolvam responsabilidades públicas na garantia de direitos e proteção integral a crianças e adolescentes poderão trazer marcas paradoxais ao PCF como a de ferramenta de criminalização da pobreza, culpabilização das famílias pelas suas necessidades, subordinação da mulher, e pior, fragilização de direitos à proteção integral de crianças e adolescentes.

\section{Universalidade e seletividade da criança no PCF}

Analisar a sustentação legal do PCF, que é estatal e federal, implica verificar como conjuga sua proposta com definições e princípios contidos: na Convenção Internacional sobre os Direitos da Criança - 1989, na CF-88 - Constituição Federal de 1988, na Lei n. 8.069/90, no ECA — Estatuto da Criança e do

8. O PFP foi criado com o objetivo de enfrentar a extrema pobreza e promover o desenvolvimento social. Considera que o enfrentamento da pobreza é missão de todos e deve priorizar intervenções simultâneas e integradas em habitação, educação, saúde, trabalho e renda. 
Adolescente, na Lei n. 13.257/16 — Marco Legal da Primeira Infầncia, nas Leis n. 8.742/93 e 12.435/11, na Loas — Lei Orgânica da Assistência Social, entre outras.

A Declaração Universal dos Direitos Humanos de 1948 trouxe a concepção da universalidade e indivisibilidade dos direitos fundamentais, contrapondo-se aos desmandos dos ditadores e a ausência de um Estado garantista. Influenciou, assim, entre outros, a Declaração Universal dos Direitos das Crianças de 1959, a Convenção sobre os Direitos das Crianças de 1989 e passou a exigir a adequação interna dos ordenamentos jurídicos dos países ratificantes, como ocorreu no Brasil, por meio da $\mathrm{CF} / 88$, em especial no art. 227, do ECA (arts. $1^{\circ}$ e $4^{\circ}$ ) com a Doutrina da Proteção Integral.

A universalidade implica o reconhecimento dos direitos à igualdade e à não discriminação. A Convenção de 1989 a consagra ao afirmar a universalidade das políticas para a infância. No art. $1^{\circ}$ define criança (menos de dezoito anos) e ressalta a não discriminação por qualquer natureza e a responsabilidade, por parte dos estados-partes, no seu atendimento, como dever de garantia e proteção (art. $2^{\circ}, 1$ e 2 ).

A CF/88 também consagrou o direito de igualdade e universalidade dos direitos fundamentais, inclusive quando define o direito à saúde, a política de assistência social, o direito à educação e a doutrina de proteção integral. Pelo princípio da universalidade é gerada a condição de sujeito de direitos, de um lado, e de dever de garantia do poder público, de outro. Observa-se, porém, que o PCF deixa de atender ao princípio da universalidade, pois deveria estar disponível para atender a todo o público prioritário, enquanto política pública, que gera expectativa de direito, mas na esteira do marco legal da primeira infância recorta (zero a seis anos) a definição de "criança" contida no ECA e dessa sub recorta a primeira infância de zero a três anos, o que contribui para a segmentação do núcleo familiar, além do fato de que a oferta para o atendimento das crianças de família em situação de vulnerabilidade não alcança a todos. Opera a fragmentação da infância transgredindo o campo normativo. Essa condução não se configura como um simples jogo de semântica, mas de decisões políticas que podem desconstruir a ideia de núcleo familiar desenhada a partir da CF/88 e enfraquecer o ECA na defesa integral dos direitos da infância. Ademais, essa fragmentação pode implicar o não reconhecimento da prioridade absoluta para algumas faixas etárias da infância. 
Outrossim, são poucas as perspectivas de continuidade do PCF dado o caráter seletivo no processo de adesão dos municípios.

Para Di Pietro (2005, p. 67 e 71), a legalidade e a supremacia do interesse público sobre o particular são princípios fundamentais do direito administrativo, mas a CF/88 inovou, definindo alguns princípios a que deve se submeter a administração pública direta e indireta, como: legalidade, impessoalidade, moralidade administrativa, publicidade e eficiência.

Entende-se que o PCF encontra-se sob violação aos princípios da eficiência e da economicidade na gestão pública. Para Meirelles (2003), o agente público tem o dever de atuar com presteza e perfeição em busca de resultados positivos para o serviço público e a comunidade. Segundo o Manual de Auditoria de Desempenho do Tribunal de Contas da União, economicidade seria a minimização dos recursos sem prejuízo dos padrões de qualidade (TCU, 1998). Para Luiz Lima (2008, p. 33): “A economicidade deve ser analisada de forma concomitante com os princípios da eficiência e da razoabilidade. Não se trata de buscar o menor custo ou de gastar menos. Cuida-se de gastar bem, atendendo às necessidades a um custo razoável".

A conjugação desses princípios coaduna-se com o ECA, legislação que abriga os direitos da infância numa perspectiva garantista com interface com o sistema de saúde, de assistência social e de educação, e tem como objetivo a garantia da proteção integral e o pleno desenvolvimento da criança e do adolescente dentro do sistema de garantias.

Para Marta Toledo (2003, p. 143), "na base da noção de proteção integral está a ideia de efetividade dos direitos fundamentais". Essa efetividade passaria pelo sistema de garantias, em que cada segmento da política pública cumpriria com sua responsabilidade protetiva.

Afinal, cada eixo do sistema de garantias (saúde, educação e assistência) traz no campo do direito formal e material o cuidado para com a primeira infância.

No ECA, Capítulo I, que trata do direito à vida e à saúde (arts. 7 ss.) encontram-se contemplados o cuidado com a gestante, a proteção da criança em seu desenvolvimento físico e psicológico, a proteção contra maus-tratos através da articulação com os serviços da assistência social e demais atores do sistema 
de garantias, além de assegurar a exigência contínua da formação profissional para quem tem o dever de prestar tais serviços.

O Capítulo IV do ECA, que trata do direito à educação, à cultura, ao esporte e ao lazer (arts. 53 ss.), enfatiza a promoção do pleno desenvolvimento da criança para o exercício da cidadania, bem como a participação dos pais ou responsáveis na construção do processo pedagógico. Traz ainda o atendimento das crianças de zero a cinco anos em creche e pré-escola, como dever do Estado e direito da criança, preceito este que atende, por sua vez, a CF/88 (art. 208) e Lei de Diretrizes e Base da Educação (art. 4º II e 29) que a ratifica. Esta última traz textualmente o dever do Estado de assegurar o pleno desenvolvimento da criança por meio da educação infantil.

Já no campo da assistência social, o Paif — Programa de Atenção Integral à Família, o Paefi - Serviço de Proteção e Atendimento Especializado a Famílias e Indivíduos e o SCFV — Serviço de Convivência e Fortalecimento de Vínculos realizam trabalho social com a família sob atenção grupal e/ou individual, em espaços públicos e em visitas domiciliares, em consonância com o que determina a NOB/Suas - Norma Operacional Básica da Assistência Social-2005.

A área da saúde - tanto quanto a da educação ou a da assistência social - conta com profissionais, funcionários estatais, com domínio técnico para tratar de cuidados e desproteção à primeira infância no que for correspondente, estando contempladas as visitas domiciliares, sobretudo na Estratégia Saúde da Família. Em contraponto, o PCF denota querer fazer, sem conhecimento profissional e sem conhecer o que já é realizado pela educação, saúde e assistência social.

Pelo registrado, não há inovação no PCF que possa justificar sua presença na gestão governamental, completando resultados que os sistemas públicos de atenção social já operam quanto ao estímulo aos cuidados familiares das crianças.

O PCF parece desconhecer o Sistema de Garantias de Direitos e se apresenta como um programa periférico, gerando expectativas de direitos sem segurança jurídica e metodológica para afiançá-los. Seu conteúdo traz enunciados de política pública sem explicitar os procedimentos concretos de seu desenvolvimento, principalmente num pretenso diálogo intersetorial com as demais políticas públicas. 
O PCF parece dispensar permissão para que um estranho adentre a intimidade da dinâmica da convivência familiar, o que revela existir autopermissividade nas determinações do PCF para adentrar as casas das famílias trajado de autoridade para ensiná-las a educar os filhos. Essa permissividade destoa de pretensa guarida constitucional e legal nas quais busca fundamentação.

Se, para os particulares, tudo é permitido, desde que a lei não o proíba, para o Estado só é permitido o que consta em lei.

\section{Autonomia da família, da mãe e da mulher}

A CF/88 e o ECA reconhecem as mudanças pertinentes ao instituto de família, formada por qualquer um dos genitores e seus descendentes, havendo igualdade na relação entre homem e mulher aqui inseridos. Este ponto centra-se na mudança no paradigma de tratamento dado à criança incluída numa estrutura familiar, realçada posteriormente na supressão da expressão pátrio poder por poder familiar (Código Civil e Lei de Convivência Familiar e Comunitária).

O PCF dissona dos fundamentos legais que orientam as políticas públicas que buscam atender às famílias e seus membros, foca a figura da mulher/mãe como cuidadora privilegiada da criança, e não menciona o instituto da paternidade responsável. Assim, viola a igualdade e ignora o conceito de família extensa, bem como as dinâmicas daquelas crianças que se encontram em situação de vulnerabilidade. O PCF, ao ser abrigado na gestão do Suas, deixa de observar o conceito de núcleo familiar que aplica, direcionado para a proteção social distributiva:

A família, independentemente dos formatos ou modelos que assume, é mediadora das relações entre os sujeitos e a coletividade, delimitando, continuamente os deslocamentos entre o público e o privado, bem como geradora de modalidades comunitárias de vida. (Brasil, 2004, p. 41)

Fica evidente que a não efetivação de políticas públicas para a promoção e a proteção do desenvolvimento integral de crianças e adolescentes é camuflado nas múltiplas elaborações de normas que fracionam o núcleo familiar, sem de fato atender as suas reais necessidades. A falta de comunicação e confiança entre 
as diferentes áreas das políticas públicas acaba por não concretizar o ideário a que se propõe.

Cada serviço quer ter a primazia das informações. Assim, a família tem que se sujeitar a prestá-las à cada equipe que bate à sua porta, ainda que sejam do mesmo segmento. A dinâmica da família em situação de vulnerabilidade passa a ser pautada, ironicamente, pelos serviços e programas que, de forma paradoxal, têm por objetivo promover seu desenvolvimento, protagonismo e autonomia.

Outrossim, o direito à privacidade garante que as informações do indivíduo e de sua família sejam respeitadas, não podendo sofrer nenhuma forma de condicionamento ou determinação para se obter os eventuais benefícios advindos de políticas de promoção e proteção da família. Ao ser operado por um agente indefinido, um visitador com baixa remuneração, dificilmente o PCF poderá ser eficaz assegurando direito socioassistencial. Estaria o direito socioassistencial, enquanto direito à proteção social distributiva, sendo suprimido? $\mathrm{O}$ procedimento imposto de invasão da privacidade nos núcleos familiares pelo PCF é igualitário para todas as classes sociais?

Mostra-se necessário um estudo aprofundado sobre o custo-benefício da violação de privacidade das famílias em diferentes atenções sociais para que se possa avaliar a garantia da efetividade dos direitos produzidos.

Para além do trato incipiente da família no PCF, é preciso examinar como ele cuida da mulher. Aparentemente, objetiva colaborar no exercício da parentalidade, fortalecendo vínculos, e o desempenho em relação à família no que se refere ao cuidado, à proteção e à educação de crianças de até seis anos. Essas ações interferem na família e na condição da mulher na família.

Quando mães lutam com seus filhos contra as correntes da indigência, da dificuldade material, e da desproteção, suas pobrezas as obrigam muitas vezes a enjeitá-los, a "dá-los para criar", a abortá-los, sem deixar registros de sua dor. A medicina tenta interferir e faz eco das demandas da Igreja do sistema colonial, incentivando o exercício correto da maternidade. Dar à luz de forma mais técnica, evitando "arroubos" e excessos com o corpo feminino, significa estar dentro de regras que interessam ao Estado metropolitano. Significa também estar distante das práticas ancilares que determinavam os partos entre comadres e de cócoras. (Del Priore, 1992, p. 59) 
Ao determinar que visitadores de nível médio compareçam semanalmente à moradia de uma família marcada pela precariedade de condições e necessidades, o Estado brasileiro, pelo PCF, financia uma operação no campo social sem provê-la de formação técnica qualificada, o que reforça a ideia de que sua preocupação é maior com o exercício de vigilância disciplinadora sobre as famílias, as mães e as mulheres pelo agente do Estado.

Não ocorrem avanços para as mulheres, mães pobres com a criação do PCF. Para essa parcela da sociedade, o Brasil contemporâneo deve conter ações do Estado com: creches, escolas em tempo integral, emprego que garanta tempo de amamentação. É limitado considerar que tudo se resolve no interior da moradia ou que são as pessoas, individualmente, que determinam o cuidado com a gestação e com a criança. Cuidar de pessoas não significa apenas cuidar de crianças, mas também mães, pois, uma mãe que tem na divisão de tarefas e cuidados o Estado como seu aliado, será muito mais feliz e criará filhos felizes.

Determinar para mulher de baixa renda o papel de única responsável pela orientação, alimentação e cuidado da criança é reforçar e criar políticas patriarcais, ou seja, o Estado se comporta como o patriarca que mantém a autoridade sobre mulheres e crianças. Ao determinar o lugar da mulher na esfera doméstica, e não como sujeito da história, afirma indiretamente que ela não é capaz de decidir sobre o cuidado e a orientação de seus filhos.

O PCF parece realizar um salto histórico às avessas ou para o passado, pois retoma a noção de políticas sociais assentadas na lógica jurídica que evoca a autoridade disciplinar do governo, afirmando relações sociais cuja base material se apoia em relações hierárquicas e solidárias entre homens que lhes possibilita controlar as mulheres. Esse modus vivendi no Brasil de antanho, pré- $\mathrm{CF} / 88$, não é mais aceitável. É preciso afiançar a promoção de direitos do cidadão independente de sua situação econômica, sobretudo das mulheres.

O PCF, de forma indigerível ao reconhecimento de direitos, instala a figura dirigente da mulher primeira-dama, mulher do lar cuidadora, subalterna, de boa vontade, que, pela sua condição destacada, de elite política, reduz a responsabilidade estatal e pública em assegurar direitos. Reforça, assim, que à mulher não cabe planejar, executar e, tampouco, gerir alguma ação política, mas sim um papel secundário, quase decorativo. 
A virtude pessoal em ser considerada bela acaba corroborando com a finalidade de tal propaganda, que utiliza uma imagem "angelical" e que ameniza a ausência de popularidade do governante como afirmado pelo jornal Folha de S.Paulo, em 6/10/2016, logo após o lançamento do programa: "Ministros estão convencidos de que a jovem Marcela, 33, traz frescor a um governo sisudo, masculino e repleto de cabeças brancas". Ou ainda, segundo um estrategista do governo: "O Planalto não está interessado em dar à mulher de Temer a aura de formuladora nem gestora de programa social, como tinha a intelectual Ruth Cardoso, mulher de FHC". Ou nas palavras de Marcela Temer: "A criança feliz não é uma política pública (...) é uma semente". 9

O Conselho Federal de Serviço Social emitiu nota, em 7/10/2016, afirmando que "o primeiro-damismo resgata a negação do direito social, a desprofissionalização das políticas sociais e a condição subalterna da mulher". Em uma segunda nota, de 7 de março de 2017, ressalta o apelo do PCF: "Para que as primeiras-damas dos estados e municípios imprimam os esforços necessários para adesão ao programa (ato obrigatório a todos os entes federados, com anuência de seus respectivos conselhos de assistência social)".

A voz imperativa desse comando vem provocando um desmonte no Suas, pois alguns municípios realizaram a aglutinação e a extinção de secretarias no campo da assistência social e alteraram suas nominações, descaracterizando sua natureza na gestão do Suas. Com isso se desconstrói a política pública de assistência social, desconsiderando sua presença por determinação constitucional como política pública de seguridade social, dever de Estado e direito do cidadão.

\section{Seletividade de municíios e abandono da universalidade da políica pública}

O PCF parte de decisão unilateral do governo federal e realiza a escolha de quase 2.660 cidades, dentre os 5.570 municípios. Pauta-se em condições favoráveis de gestão, secundarizando a necessidade da população.

9. Marcela Temer, embaixadora do programa, em sessão solene realizada em 9 de fevereiro. Disponível em: <https://www.youtube.com/watch?v=TvlW3fKMz4I>. Acesso em: 15 abr. 2017. 
A esse propósito, o Suas 10 advertia: "O Suas é política de Estado, não de governantes ou de governos". Ao sublinhar essa característica, Sposati acrescentou que "o fato de que o cidadão esteja desprotegido não é justificativa para que qualquer simplificação ou precarização do processo de atenção seja realizado sob a condição de um alívio". Por fim pontua: "O Suas não é de um estado ou de uma cidade" (p. 13).

Os construtores do PCF não se baseiam na universalidade de cobertura, consideram que a autonomia precede a universalidade, porém não justificam o que isso significa. A participação dos entes federativos ocorre por meio de adesão, formalizada por Termo de Aceite, conforme a Resolução n. 05/16, que selecionou os entes federativos estaduais, ressalvando que a adesão deve ser ratificada pelo respectivo Conselho Estadual de Assistência Social. Quanto aos municípios, a seleção identifica aqueles com ID-Cras de pelo menos três pontos ou padrão médio de operação.

Foram selecionados 2.622 municípios, dos quais 97,5\% já finalizaram o termo de aceite, sendo que ofertarão 373.300 vagas. Mas esse número atinge só $53 \%$ dos 5.570 municípios brasileiros.

Quadro 1 - Municípios eleitos

\begin{tabular}{|c|c|c|c|}
\hline A & B & C & D \\
\hline AC & 22 & 17 & 28 \\
\hline AM & 62 & 47 & 90 \\
\hline PA & 144 & 89 & 251 \\
\hline AP & 16 & 04 & 19 \\
\hline MT & 141 & 27 & 176 \\
\hline GO & 246 & 96 & 280 \\
\hline MS & 79 & 27 & 134 \\
\hline MA & 217 & 164 & 316 \\
\hline CE & 184 & 170 & 388 \\
\hline
\end{tabular}

\begin{tabular}{|c|c|c|c|}
\hline A & B & C & D \\
\hline PB & 223 & 167 & 265 \\
\hline SE & 75 & 63 & 108 \\
\hline BA & 417 & 311 & 613 \\
\hline ES & 78 & 19 & 145 \\
\hline MG & 853 & 243 & 1140 \\
\hline PE & 185 & 132 & 323 \\
\hline PI & 224 & 173 & 273 \\
\hline PR & 399 & 89 & 564 \\
\hline RJ & 92 & 50 & 453 \\
\hline
\end{tabular}

\begin{tabular}{|c|c|c|c|}
\hline A & B & C & D \\
\hline $\mathrm{RN}$ & 167 & 126 & 220 \\
\hline $\mathrm{RO}$ & 52 & 16 & 60 \\
\hline $\mathrm{RR}$ & 15 & 14 & 23 \\
\hline $\mathrm{RS}$ & 497 & 72 & 585 \\
\hline $\mathrm{SC}$ & 295 & 11 & 368 \\
\hline $\mathrm{DF}$ & 01 & 01 & 27 \\
\hline $\mathrm{SP}$ & 645 & 222 & 1103 \\
\hline $\mathrm{TO}$ & 139 & 43 & 151 \\
\hline $\mathrm{AL}$ & 102 & 82 & 173 \\
\hline
\end{tabular}

Fontes: Programa Criança Feliz no Suas. Censo-Suas 2016.

Nota: As colunas A apresentam as UF; as colunas B, o número de municípios; as colunas $\mathrm{C}$, o número de municípios aderentes por UF; as colunas D, o número de Cras nas UF. 


\section{Limites orçamentários e o orçamento do PCF}

O orçamento de 2017 prevê para o PCF R 328 milhões (0,4\% do Fundo Nacional de Assistência Social/17), para uma meta de 700 mil crianças, embora indique 373 mil vagas para receber visitas domiciliares.

Vale a pena mencionar que estudo efetuado pela Confederação Nacional de Municípios - CNM sobre o financiamento do PCF indica a presença de subfinanciamento e insegurança jurídica:

Como não se trata de lei federal, não há garantia da continuidade do programa ou da regularidade dos repasses financeiros nem da atualização anual dos valores transferidos aos municípios. Como exemplo dessa insegurança, é importante lembrar as mudanças recentes definidas por medidas provisórias no Programa Brasil Carinhoso.

Essa fragilidade legal poderá criar lacunas em reajustes de financiamento, o que agrava a situação de custeio que se mostra insuficiente para responder pelas despesas de pagamento de pessoal e encargos. O orçamento previsto não consegue cofinanciar mais de 50\% das despesas do PCF. Foram considerados a remuneração dos encargos trabalhistas e sociais, as despesas com pagamentos de impostos, as contribuições sociais, FGTS — Fundo de Garantia por Tempo de Serviço, férias, décimo terceiro salário, salários proporcionais e demais encargos sociais e trabalhistas. Incluíram ainda despesas administrativas e operacionais, despesas de aluguel, transporte, computador, concessionárias, material pedagógico e de escritório, formação e capacitação, motorista etc., fundamentais para seu funcionamento e que demandam verbas para custeio.

Por consequência, o valor financeiro a ser repassado aos municípios cobre de $32 \%$ a $65 \%$ da despesa, ocorrendo variação em função do porte. Os municípios deverão arcar com a contrapartida, que poderá chegar a até 68\%. Os Quadros 2 e 3 mostram essas variações. 
Quadro 2 - Repasses para os municípios previstos pelo PCF (valor R\$ ano)

\begin{tabular}{|l|c|c|c|c|}
\hline Municípios & $\begin{array}{c}\text { Repasse Governo } \\
\text { Federal (R\$) }\end{array}$ & $\begin{array}{c}\text { Custo Municipal } \\
\text { (R\$) }\end{array}$ & \% federal & \% município \\
\hline Porte I & $60.000,00$ & $92.259,64$ & 65 & 35 \\
\hline Porte II & $90.000,00$ & $150.185,41$ & 60 & 40 \\
\hline Médio e grande & $120.000,00$ & $369.038,56$ & 33 & 68 \\
\hline
\end{tabular}

Fonte: CNM.

Quadro 3 - Hipóteses de custeio dos visitadores nos municípios - PCF

\begin{tabular}{|l|c|c|}
\hline Hipóteses & Visitadores RS & Supervisores RS \\
\hline $1^{\mathrm{a}}-$ Rais & 937,00 & $1.300,00$ \\
\hline $2^{\mathrm{a}}-$ MDSA & $1.600,00$ & $3.000,00$ \\
\hline
\end{tabular}

Fonte: CNM.

A primeira hipótese de remuneração de visitadores é referenciada na Rais — Relação Anual de Informações Sociais; a segunda é indicada pelo MDSA. Nesse caso, sua contrapartida será ainda maior, pois o valor de repasse pelo governo federal ao visitador é de R $\$ 50$ por família/mês, o que independe da escolha salarial adotada pelo município. Assim, municípios de médio e grande portes irão arcar com $82,4 \%$ do valor do programa.

Outra observação a ser levada em conta refere-se ao congelamento dos gastos sociais com previsão de não expansão do orçamento. A partir dessa constatação, cabe a pergunta: qual ação em desenvolvimento será reduzida para a implantação do PCF?

Não haverá repasse do governo estadual, e o repasse federal destina-se a pagar somente doze meses, o pagamento do décimo terceiro salário vai recair para os municípios, como contrapartida ao repasse federal.

\section{Impactos no Suas}

O princípio seletivo do PCF transgride o estabelecido como universalidade da política de assistência social e do Suas ao desconsiderar o pressuposto do 
princípio democrático da igualdade de direito no acesso ao atendimento, sem discriminação de qualquer natureza e com extensão da abrangência a toda população dos 5.570 municípios brasileiros

$\mathrm{O}$ alcance da universalidade na proteção social distributiva que compete à política pública de assistência social e ao Suas, seu sistema gestor, está referido a todos que utilizam seus serviços, aos três tipos de benefícios (eventual, continuado e transferência de renda), e aos cidadãos que acorrem ao CADÚnico para obter benefícios em outras políticas sociais.

A assistência social busca que as atenções na política sejam acessíveis a todos(as), considerando as diversidades e especificidades de públicos e territórios. É o horizonte que se projeta para orientar a próxima década.

Dentre os públicos contidos na Resolução CNAS n. 19/16 (art. 3º, II), encontram-se crianças de até seis anos afastadas do convívio familiar em razão da aplicação de medida protetiva. Contudo, há de se observar que essas crianças e suas famílias, por estarem sob a égide do ECA, art. 90, são acompanhadas por equipes técnicas do Serviço de Acolhimento Institucional para Crianças e Adolescentes (Saica), Creas e das Varas da Infância e Juventude, tornando-se dispensável a inclusão de mais visitadores a essas famílias, sob pena até de causar prejuízos às relações já referenciadas e contrarreferenciadas dos agentes do SGD.

É estruturante do Suas a intersetorialidade, descrita no

II Plano Decenal Nacional de Assistência Social, a articulação entre as políticas públicas por meio do desenvolvimento de ações conjuntas destinadas à proteção social, à inclusão e ao enfrentamento das desigualdades sociais identificadas. Supõe a implementação de ações integradas e a superação da fragmentação na atenção às necessidades sociais da população. Envolve a agregação de diferentes setores sociais em torno de objetivos comuns e deve ser princípio orientador da construção das redes municipais, regionais, estaduais e do Distrito Federal. (Sposati, 1988, p. 30)

As ações que o PCF indica já são contempladas na assistência social pelo Paif e pelo Paefi, executadas pelos Cras e Creas, bem como pela rede de serviços socioassistenciais referenciada a estes. O PCF sobrepõe ações já previstas pela PNAS 2004 "que afirma realizar de forma integrada às políticas setoriais, 
considerando as desigualdades socioterritoriais, visando seu enfrentamento, à garantia dos mínimos sociais, ao provimento de condições para atender contingências sociais e à universalização dos direitos sociais" (PNAS/04,p.33), provendo serviços, programas, projetos e benefícios de proteção social básica e especial para famílias, indivíduos e grupos que deles necessitarem, bem como assegurando que as ações no âmbito da assistência social tenham centralidade na família e que garantam a convivência familiar e comunitária.

A superposição por visitadores sem vínculo profissional com os órgãos públicos responsáveis poderá causar a desqualificação dos profissionais que operam com políticas referenciadas.

A forma de busca ativa contida no PCF, sem trazer respaldos que acresçam algo ao já instituído, não mostra efetivamente a que o programa vem. Parece que seus idealizadores são marcados pelo desconhecimento da dinâmica da política de assistência social em seu território concreto.

A equipe de visitadores tem periodicidade variada, sendo um para cada 25 famílias, com presença referente ao membro de 25 famílias, intervalo de tempo que se altera com a presença prioritária ao PCF de crianças com até 36 meses de idade.

Quadro 4 - Quantificação de visitas para os visitadores por faixa etária da criança

\begin{tabular}{|c|c|}
\hline \multicolumn{2}{|c|}{ Visitador - total de 25 famílias } \\
\hline Público prioritário & Visitas mensais \\
\hline Gestante & 1 \\
\hline Crianças de 0 a 24 meses (PBF e BPC) & 2 \\
\hline Crianças de 24 meses a 36 meses (PBF) & 3 \\
\hline Crianças de 24 a 72 meses (BPC) & 3 \\
\hline
\end{tabular}

Fonte: CNM.

Ao indicar a coordenação do programa para o gestor da assistência social, qual autonomia, autoridade e competência técnica para subsidiar outras políticas envolvidas que essa gestão terá? A intersetorialidade é citada, mas não é 
detalhada operativamente, razão pela qual atribuir a gestão do PCF à assistência social é indicar um caminho que não tem condições de ser trilhado.

\section{Considerações finais sobre a semente da felicidade por decreto}

Um governo decretar a felicidade do povo em um Estado democrático de direito, dirigindo um dispositivo aos mais miseráveis, dentre eles crianças e mulheres, traz imediata relação com o pão e circo romano próprio dos césares. $\mathrm{Na}$ sociedade do terceiro milênio a presença da violência traz a demanda pela segurança, que na política e na assistência social é direcionada para a garantia de segurança social com provisão de atenções que garantam o sentir-se protegido e o contar com determinadas atenções sociais.

Colocar em um mesmo paradigma proteção social e felicidade como reponsabilidades estatais é, no mínimo, sequestrar liberdades dos cidadãos. São tantas inquietações que acometem os humanos, como vida e morte, liberdade, amor, bem e mal, que considerar que o Estado possa decretar o que é uma criança feliz e se arrogar fazedor dessa felicidade por meio de visitas é tão prenhe de sentido que chega a ser hilário.

Muito embora a filosofia não tenha apresentado uma solução definitiva para a questão humana da felicidade, o governo brasileiro pretende fazê-lo "por decreto", instituindo a felicidade "a gestantes, crianças de até três anos e suas famílias beneficiárias do PBF; crianças de até seis anos e suas famílias beneficiárias do BPC; e crianças de até seis anos afastadas do convívio familiar em razão da aplicação de medida de proteção" - que, ao talante e alvedrio do governo foram consideradas "pessoas infelizes" e, em razão disso, foram eleitas para o alcance da felicidade.

Ao direcionar os sujeitos do PCF ocorre odiosa e preconceituosa discriminação, excluindo do programa aqueles que por decreto são considerados crianças e famílias felizes, ao mesmo tempo que indica aqueles que, também por decreto, considera crianças e famílias infelizes. Não pode o Estado, a pretexto de proporcionar felicidade às pessoas, estabelecer aprioristicamente quais são as pessoas infelizes. 
É certo que a felicidade ou o direito a sua busca é objeto de dispositivos legais e fundantes em diversos países. Entre nós há um Projeto de Emenda à Constituição (PEC n. 19/10) para inseri-la no texto constitucional, porém é muito claro o significado da inserção como um ideal simbólico, o que não ocorre no PCF, que, pretensiosa e falaciosamente, traz em seu bojo a mensagem de que a execução, pelos agentes do Estado, de ações nele previstas, proporcionará felicidade às pessoas ali consideradas, por decreto, infelizes.

$\mathrm{O}$ PCF se divorcia flagrantemente das bases constitucionais e legais que conformam o sistema da proteção integral. O breve estudo aqui apresentado aponta indícios contundentes de que o PCF, a pretexto de corroborar com a promoção e a proteção das crianças, tão somente vem a contribuir para um retrocesso na política da proteção integral.

O PCF contraria o princípio da universalidade assegurado pela Convenção sobre os Direitos da Criança, a CF/88, o ECA e demais normas correlatas. Deve-se registrar também que nem no recorte que faz para o atendimento às crianças de família em situação de vulnerabilidade, o referido princípio é atendido.

Assevera-se, ainda, que nesse universo disposto há um retrocesso à chamada cultura do primeiro-damismo em uma inadequação à toda prova, quiçá uma afronta a princípios constitucionais e legais, a exemplo do princípio da moralidade. Implicitamente, é possível até engendrar um movimento de desobrigação do dever do Estado quanto às responsabilidades frente às políticas públicas essenciais para uma vida digna.

Por fim, registra-se o desrespeito à dinâmica do núcleo familiar, como este é concebido na $\mathrm{CF} / 88$ e nas leis, em uma desatenção aos direitos da criança, que tão somente traz como significância uma forma de controle social.

Ademais, o PCF não especifica a origem orçamentária para a consecução do programa, subentendendo-se que retira verbas de outras políticas para fazer o que já é feito pelos programas de saúde e de assistência social, sem critérios objetivos para avaliar sua efetividade.

Recebido em 27/4/2017 - Aprovado em 12/6/2017 


\section{Referências bibliográficas}

BRASIL. Constituição da República Federativa do Brasil. 1988.

. Lei n. 8.069, de 13 de julho de 1990. Estatuto da Criança e do Adolescente, 1990.

. Lei n. 8.742, de 7 de dezembro de 1993. Lei Orgânica da Assistência Social, 1993.

. Ministério do Desenvolvimento Social e Combate à Fome. Política Nacional de Assistência Social — PNAS. Brasília, 2004.

. Ministério do Desenvolvimento Social e Combate à Fome. Norma Operacional Básica do Sistema Único de Assistência Social NOB/Suas. Brasília, 2005.

. Suas 10: Diversidade no Suas: realidade, respostas, perspectivas. Brasília: Ministério do Desenvolvimento Social e Combate à Fome; Secretaria Nacional de Assistência Social — SNAS, 2015.

. Ministério do Desenvolvimento Social e Combate à Fome - COMISSÃO INTERGESTORES TRIPARTITE. Publicado no DOU de 18/11/2016 (nº 221, Seção 1, pág. 79), que pactua critérios de partilha para o financiamento federal das ações do Programa Criança Feliz no Sistema Único de Assistência Social para os exercícios de 2016 e 2017.

. Ministério do Desenvolvimento Social e Combate à Fome. Resolução no ${ }^{\circ}$, de 24 novembro de 2016. Institui o Programa Primeira Infância no Sistema Único de Assistência Social - SUAS, nos termos do $§ 1^{\circ}$ do art. 24 da Lei $n^{\circ} 8.742$, de 7 de Dezembro de 1993.

CFESS. Nota pública - Primeiro-damismo, voluntariado e a felicidade da burguesia brasileira, de 7/10/2016. Disponível em: <http://www.cfess.org.br/visualizar/noticia/ cod/1301>. Acesso em: 16 mar. 2017.

. Nota pública Por que dizer não ao Programa Criança Feliz, de 07/03/2017.

Disponível em: <http://www.cfess.org.br/js/library/pdfjs/web/viewer.html?pdf=/ arquivos/2017-NotaPublicaCFESS-NaoAoProgramaCriancaFeliz.pdf $>$. Acesso em: 16 mar. 2017.

CONFEDERAÇÃO NACIONAL DOS MUNICÍPIOS-Programa Criança Feliz Primeira Infância no Suas. Assistência Social — Março de 2017. <www.cnm.org.br>. 
DEL PRIORE, M. A mulher na história do Brasil. 3. ed. São Paulo: Contexto, 1992.

DI PIETRO, M. S. Z. Direito administrativo. 18. ed. São Paulo: Atlas, 2005.

FOLHA DE S.PAULO. Análise. Governo adere ao primeiro-damismo para suavizar imagem sisuda e masculina, 6 out. 2016. Disponível em: $<$ http://www1.folha.uol.com.br/ poder/2016/10/1820358-governo-adere-ao-primeiro-damismo-para-suavizar-imagemsisuda-e-masculina.shtml>. Acesso em: 17 mar. 2017.

GOMES, M. R. C. S. Nacionalização da política de assistência social e governos estaduais no Brasil: o caso do estado de São Paulo. Tese (Doutorado em Serviço Social). PUC, São Paulo, 2008.

LIMA, L. H. Controle externo. Rio de Janeiro: Elsevier, 2008.

MACHADO, Martha de Toledo. A Proteção Constitucional de Criança e Adolescente e os Direitos Humanos. Barueri: Ed. Manole, 2003.

MEIRELLES, Hely Lopes. Direito administrativo brasileiro. São Paulo: Malheiros, 2003.

PERNAMBUCO. Lei n. 13.959, de 15 de dezembro de 2009. Dispõe sobre o Programa Mãe Coruja Pernambucana.

PROGRAMA CRIANÇA FELIZ. Disponível em: < http://www.cnm.org.br/cms/ biblioteca/ProgramaCriancaFeliz_PrimeiraInfanciaNoSuas.pdf $>$. Acesso em: 19 abr. 2017.

SPOSATI, A. Vida urbana e gestão da pobreza. São Paulo: Cortez, 1988.

TRIBUNAL DE CONTAS DA UNIÃO — TCU. Manual de Auditoria de Desempenho. Brasília: Tribunal de Contas da União, 1998. Disponível no TCU em: <http://www. gestaosocial.org.br/conteudo/parceiros/fapesb/referencia/manual-de-auditoria-dedesempenho-tcu.doc $>$. 